Tohoku J. exp. Med., 1971, 104, 171-175

\title{
Degradation of the Side-chain of Cortisol by Lens Homogenate
}

\author{
Shigeru Ono, Hiroko Hirano and Kijuro Obara \\ Department of Biochemistry, School of Medicine, Iwate \\ Medical University, Morioka
}

Ono, S., Hirano, H. and Obara, K. Degradation of the Side-chain of Cortisol by Lens Homogenate. Tohoku J. exp. Med., 1971, 104 (2), 171-175Degradation of 17,2l-dihydroxy-20-ketone side-chain of cortisol by lens homogenate was investigated and a fairly active degradation of adrenocortical steroid in the lens was verified. The assay system required the addition of nicotinamide adenine dinucleotide. Optimal $\mathrm{pH}$, optimal temperature and the optimal medium composition for activity were also determined. The degradation product of cortisol after loss of the side-chain was identified to be $11 \beta$-hydroxyandrost-4-ene-3,17dione by paper chromatography and scanning method using cortisol $-4{ }^{14} \mathrm{C}$ as substrate. lens; cortisol

It is of interest to know how adrenocortical steroids are metabolized in the lens but no information is hitherto available concerning the metabolism of cortisol in the lens.

In the present study, the authors attempted to investigate the degradation of the 17,21-dihydroxy-20-ketone side-chain of cortisol by lens homogenate and its optimal assay condition in order to clarify the steroid metabolism in the lens.

\section{Materials and Methods}

Total lens homogenates of bovine, pig and rat lenses were used. The homogenization medium routinely employed was $0.15 \mathrm{M}$ potassium chloride. Homogenization in distilled water resulted in $35 \%$ loss of activity as compared with homogenization in $0.15 \mathrm{M}$ potassium chloride. The incubation medium employed was changed with the progress of the work to the most suitable one. The incubation was carried out in test tubes anaerobically at $37^{\circ} \mathrm{C}$. Details of the incubation conditions are described in respective table and figures.

After the incubation, the reaction mixtures were extracted in 5 volumes of chloroform. The chloroform layer was washed once with $1 / 4$ volume of $0.1 \mathrm{~N} \mathrm{NaOH}$, once with $1 / 4$ volume of $0.1 \mathrm{~N} \mathrm{HCl}$, and once with $1 / 4$ volume of water. An aliquot of the washed chloroform layer was dried and the residue was dissolved in methanol. To the sample in $1 \mathrm{ml}$ of methanol were added $8 \mathrm{ml}$ of phenylhydrazine in acid and the solution was heated at $60^{\circ} \pm 1^{\circ} \mathrm{C}$ for $20 \mathrm{~min}$. It was cooled with running tap water for $3 \mathrm{~min}$, and its optical density (a) was compared with that of a methanol-sulfuric acid phenylhydrazine blank at $410 \mathrm{~m} \mu$. In order to correct for interfering substances which yielded color in sulfuric acid solution, a duplicate sample was treated as above without phenylhydrazine. The optical density (b) was compared with that of a methanol-sulfuric acid blank at $410 \mathrm{~m} \mu$.

Received for publication, December 14, 1970. 
The difference in optical densities, $a-b$, was proportional to the quantity of 17,21-dihydroxy-20-ketosteroid in the sample. Color intensities were estimated by a Hitachi 139 spectrophotometer.

Identification of $11 \beta$-hydroxyandrost-4-ene-3,17-dione as a product of side-chain loss of cortisol was performed in the following way. $0.2 \mu \mathrm{Ci}$ of cortisol-4-14 $\mathrm{C}$ was incubated with bovine lens homogenate at an optimal assay condition which gave a maximum efficiency of side-chain loss. Cortisol-4-14 $\mathrm{C}$ with a specific activity of $57.9 \mathrm{mCi} / \mathrm{m}$ moles was purchased from Radio-Chemical Centre, England. Incubation mixtures were extracted with substantial amounts of ethylacetate. The organie solvent was dried under a reduced pressure. The residue was partitioned between $80 \%$ aqueous methanol and petroleum ether (b.p. $30-60^{\circ} \mathrm{C}$ ), and the methanol phase was evaporated to dryness. The dried residue was dissolved in a small volume of a mixture of methylene dichloride and methanol (1:1), then applied to sheets of Watman No. 1 paper $(5 \times 40 \mathrm{~cm})$ and chromatographed in the system B5 (benzene-methanol-water, 100:50:50 by vol) of Bush and Willoughby (1957) at $37^{\circ} \mathrm{C}$ for $3 \mathrm{hr}$. The chromatography brought about the separation of corticosterone, cortisone and $11 \beta, 17 \alpha, 20 \beta$-21-tetrahydroxypregn-4-ene-3-one as side-chain metabolites of cortisol which reduced phenylhydrazine with their ketone groups and $11 \beta$-hydroxyandrost-4ene-3,17-dione as a product of side-chain loss of cortisol which showed no reducing ability. The position of $11 \beta$-hydroxyandrost-4-ene-3,17-dione fraction was determined with the aid of ultraviolet absorption and of paper chromatogram scanner and by comparison with the standard steroid chromatographed simultaneously.

\section{Results}

Preliminary experiments indicated that a significant loss of the 17,21dihydroxy-20-ketone side-chain of cortisol was brought about when cortisol was incubated with whole homogenates of bovine, pig or rat lenses as shown in Table 1. The rate of reaction increased with the addition of nicotinamide adenine dinucleotide (Fig. 1), clearly implicating the involvement of pyridine nucleotides in the reaction. The time course of the reaction was shown in Fig. 2. The reaction proceeded linearly for about $120 \mathrm{~min}$, then declined. The $\mathrm{pH}$-activity curve was fairly sharp as shown in Fig. 3, the $\mathrm{pH}$ optimum being at 7.2 to 7.4. The reaction rate also increased with the increase of temperature, reaching a maximum at $37^{\circ} \mathrm{C}$; the rate fell off sharply at higher or lower temperatures than $37^{\circ} \mathrm{C}$.

TABLE 1. The side-chain loss of cortisol by bovine, pig or rat lens homogenates.

\begin{tabular}{l|c}
\hline & $\mu \mathrm{g} / \mathrm{g}$ \\
\hline Bovine lens & $340 \pm 62.6$ \\
Pig lens & $669 \pm 198.5$ \\
Rat lens & $360 \pm 128.2$
\end{tabular}

Reaction mixtures contained, in a final volume of $5 \mathrm{ml}: 150 \mathrm{mg}$ of whole lens homogenized in $0.15 \mathrm{M}$ potassium chlorided, $200 \mu \mathrm{M}$ potassium phosphàte buffer ( $\mathrm{pH} 7.4$ ), $100 \mu \mathrm{g}$ cortisol and $0.75 \mu$ mole NAD. Incubation was carried out for 150 min at $37^{\circ} \mathrm{C}$. Loss of side-chain represented the amount of lost cortisol per gram of wet weight of lens. Each mean was obtained from 5 experiments. 


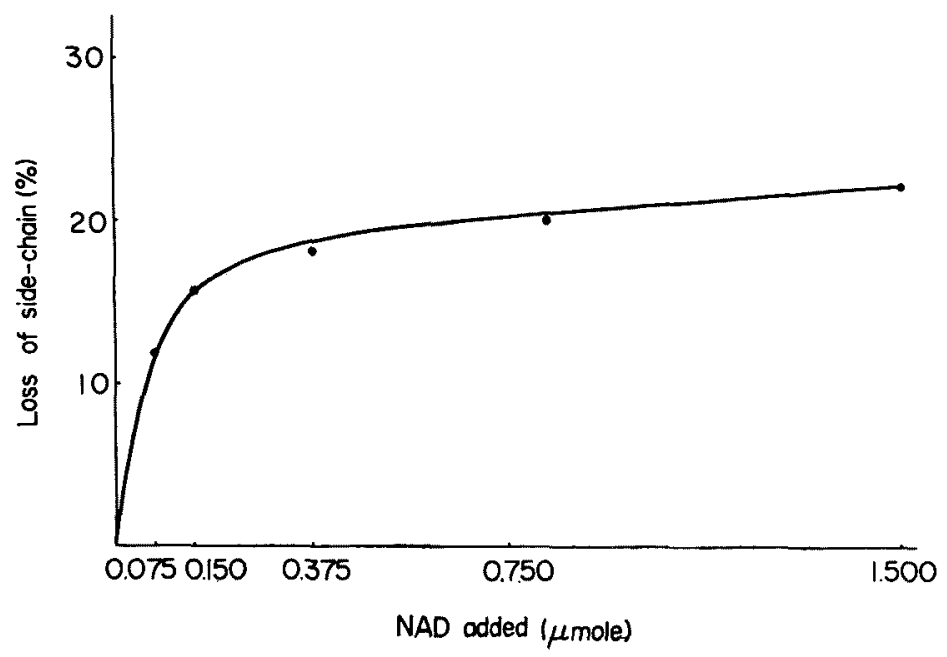

Fig. 1. Effect of addition of nicotinamide adenine dinucleotide. Reaction mixtures contained, in a final volume of $5 \mathrm{ml}: 150 \mathrm{mg}$ of whole bovine lens homogenized in $0.15 \mathrm{M}$ potassium chloride, $200 \mu \mathrm{M}$ potassium phosphate buffer (pH 7.4), $100 \mu \mathrm{g}$ cortisol and indicated amounts of NAD. Reactions were carried out for $150 \mathrm{~min}$ anaerobically at $37^{\circ} \mathrm{C}$. The percentage of side-chain loss was calculated against the amount of cortisol added.

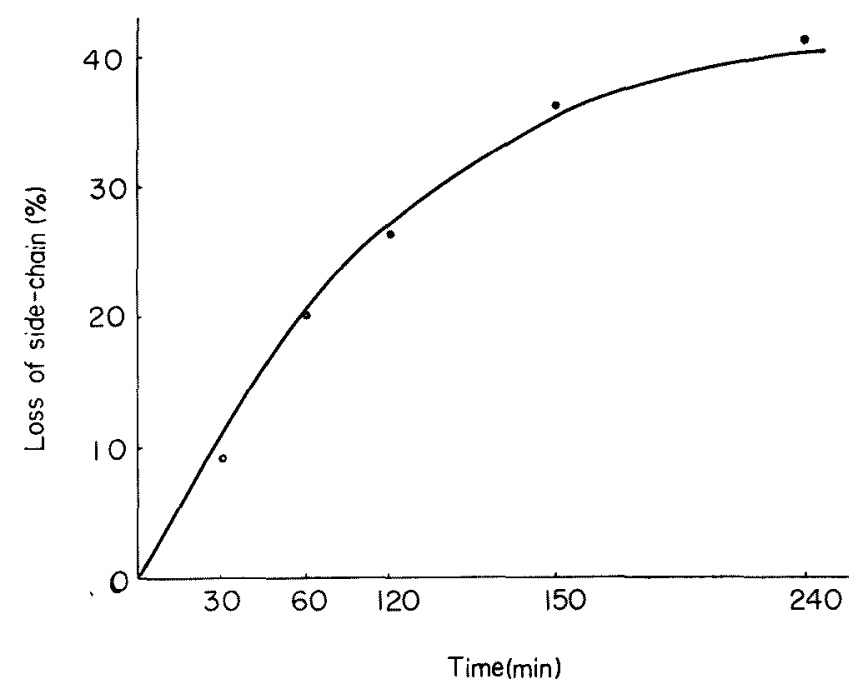

Fig. 2. Time course of the reaction. Reaction mixtures contained, in a final volume of $5 \mathrm{ml}: 150 \mathrm{mg}$ of whole bovine lens homogenized in $0.15 \mathrm{M}$ potassium chloride, $200 \mu \mathrm{M}$ potassium phosphate buffer ( $\mathrm{pH} 7.4), 100 \mu \mathrm{g}$ cortisol and $0.75 \mu$ mole NAD. Reactions were carried out for $30,60,120,150$ and $240 \mathrm{~min}$, respectively, anaerobically at $37^{\circ} \mathrm{C}$. 


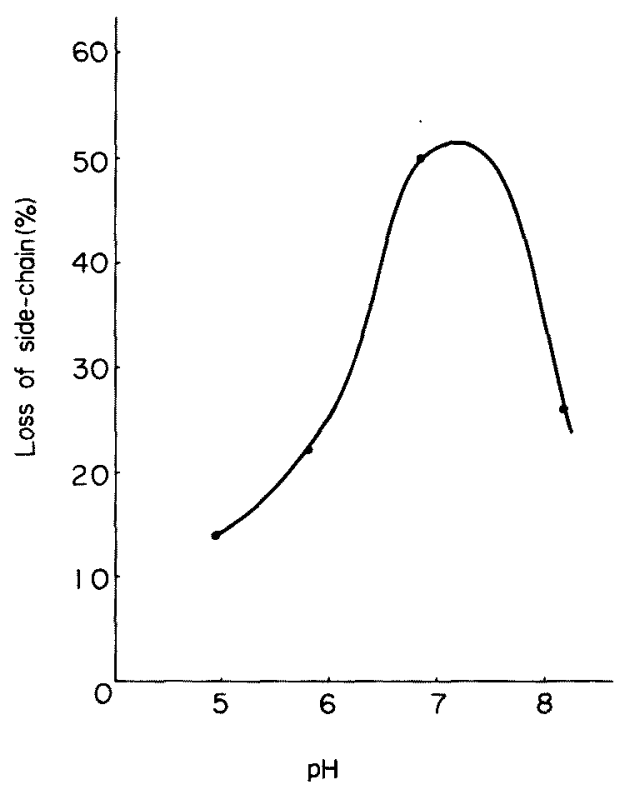

Fig. 3. $\mathrm{pH}$ optimum. Reaction mixtures contained in a final volume of $5 \mathrm{ml}: 150 \mathrm{mg}$ of whole bovine lens homogenized in $0.15 \mathrm{M}$ potassium chloride, $100 \mu \mathrm{g}$ cortisol, $\mathrm{K}_{2} \mathrm{HPO}_{4}$ citrate buffer, $0.75 \mu$ mole NAD. Other conditions were the same as in Fig. 1.

\section{Discussion}

The present study has demonstrated for the first time that there is a fairly active metabolism of adrenocortical steroids in the lens homogenate. As an indicator of the metabolism of cortisol, we employed the assay of cortisol $\mathrm{C}_{17}-\mathrm{C}_{20}$ lyase activity in the lens which catalyzes the degradation of cortisol side-chain to the $11 \beta$-hydroxyandrost-4-ene-3,17-dione. Metabolites of cortisol from human blood, urine and from synovial fluid have been reported by many authors (Porter and Silber 1950, Fukushima et al. 1955, Bush and Willoughby 1957, Ichikawa 1966, Tawfik et al. 1967, Tawfik et al. 1968).

Corticosterone, cortisone, $11 \beta, 17 \alpha, 20 \beta$-21-tetrahydroxypregn-4-ene-3-one and $11 \beta$-hydroxyandrost-4-ene-3,17-dione were separated by the above described method from the incubation mixture of lens homogenate with cortisol- $4-^{14} \mathrm{C}$.

The fact that the side-chain of cortisol is lost by lens homogenate indicates that the activity of cortisol $\mathrm{C}_{17}-\mathrm{C}_{20}$ lyase is fairly high in the lens and this pattern of metabolism would also be applicable to the metabolic pattern of adrenocortical steroids which were administered either orally or locally as an antiinflammatory drug for therapeutic purposes in the field of ophthalmology.

Recently, the posterior subcapsular cataracts in which opacities lay under the capsule at the posterior part of the lens have been given attention as one of the secondary effects of adrenocortical steroid administration (Spencer and Andelman 1965, Fürst et al. 1966, Williamson et al. 1969). Lens protein 
metabolism may be involved in the pathogenesis of the senile cataract, and therefore the metabolism has been extensively studied. But, the influence of adrenocortical steroid on the turnover of the lens protein has not been clarified yet (Lerman 1964). Experimentally and clinically, it has been shown that administration of adrenocortical hormone induces the promotion of protein catabolism and the inhibition of protein anabolism (Clark 1953, Reiss et al. 1959, Wool and Weinshelbaum 1959, Izzo and Glasser 1961, Crews 1963). Therefore, the long term oral administration of adrenocortical steroids influences gradually the lens protein turnover and may result in opacification of the lens such as the posterior subcapsular cataract.

\section{References}

1) Bush, I.E. \& Willoughby, M. The excretion of allo tetrahydrocortisol in human urine. Biochem. J., 1957, 67, 689-700.

2) Clark, I. The effect of cortisone upon protein synthesis. J. biol. Chem., 1953, 200, 69-76.

3) Crews, S.J. Posterior subcapsular lens opacities in patients in long-term corticosteroid therapy. Brit. med. J., 1963, 5346, 1644-1647.

4) Fukushima, D.K., Leeds, N.S., Bradlow, H.L., Kritchevsky, T.H., Stokem, M.B. \& Gallagher, T.F. The characterization of four new metabolites of adrenocortical hormones. J. biol. Chem., 1955, 212, 449-460.

5) Fürst, C., Smiley, W.K. \& Ansell, B.M. Steroid cataract. Ann. rheum. Dis,, 1966, 25, 364-368.

6) Ichikawa, Y. Metabolism of cortisol-4- ${ }^{14} \mathrm{C}$ in patients with infectious and collagen diseases. Metabolism, 1966, 15, 613-625.

7) Izzo, J.L. \& Glasser, S.R. Comparative effects of glucagon, hydrocortisone and epinephrine on the protein metabolism of the fasting rat. Endocrinology, 1961, 68, 189-198.

8) Lerman, S. Cataracts, Chemistry, Mechanism, and Therapy. Charles C. Thomas Publisher, Springfield Illinois U.S.A., 1964, p. 61.

9) Porter, C.C. \& Silber, R.H. A quantitative color reaction for coirtsone and related 17, 21-dihydroxy-20-ketosteroids. J. biol. Chem., 1950, 185, 201-207.

10) Reiss, E. \& Kipnis, D. The mechanism of action of growth hormone and hydrocortisone on protein synthesis in striated muscles. J. Lab. clin. Med., 1959, 54 937-938.

11) Spencer, R.W. \& Andelman, S.Y. Steroid cataracts. Posterior subcapsular cataract formation in rheumatoid arthritis patients on long term steroid therapy. Arch. Ophthal., 1965, 74, 38-41.

12) Tawfik, M.A.E., Gustafson, G.M. \& Wong, D.G. Comparative metabolism in vivo of $4^{14} \mathrm{C}$ cortisol in synovial fluid in the normal, rheumatoid and osteoarthritic knee. Biochim. biophys. Acta, 1967, 137, 375-387.

13) Tawfik, M.A.E., Murray, W.R. \& Anderson, C.E. In vivo catabolism of $4-{ }^{14} \mathrm{C}$ cortisol in synovial fluid of the rheumatoid and osteoarthritic knee. Arthritis. Rheum., 1968, 11, 178-183.

14) Williamson, J., Paterson, R.W.W., McGavin, D.D.M., Jasani, M.K., Boyle, J.A. \& Doig, W.M. Posterior subcapsular cataracts and glaucoma associated with long-term oral corticosteroid therapy. In patients with rheumatoid arthritis and related conditions. Brit. J. Ophthal., 1969, 53, 361-372.

15) Wool, I.G. \& Weinshelbaum, E.I. Incorporation of ${ }^{14} \mathrm{C}$-amino acids into protein of isolated diaphragms: role of the adrenal steroids. Amer. J. Physiol., 1959, 197, 1089-1092. 